\title{
“Soy un papá súper normal”: Experiencias parentales de hombres gay en Chile
}

\author{
Florencia Herrera \\ Universidad Diego Portales, Santiago, Chile. \\ Email: florencia.herrera@udp.cl \\ Constanza Miranda \\ Universidad de Chile, Santiago, Chile. \\ Email: constanzamsch@gmail.com \\ Yanko Pavicevic \\ Universidad Diego Portales, Santiago, Chile. \\ Email: yanko.pavicevic@mail.udp.cl

\section{Valentina Sciaraffia} \\ Universidad de Chile. Santiago, Chile. \\ Email: valesciaraffia@gmail.com
}

Resumen: Las identidades de 'padre' y 'homosexual' suelen verse como mutuamente excluyentes. El propósito de este artículo es explorar las experiencias de paternidad de hombres homosexuales en Chile. Se realizaron entrevistas en profundidad a 14 padres que se auto identifican como homosexuales o gay y que han tenido hijos tanto en el marco de una relación heterosexual, como en el contexto de una relación homosexual (a través de gestación subrogada o acuerdo de coparentalidad). Los resultados muestran que las experiencias de paternidad de los padres gay no son muy diferentes a las de los padres heterosexuales. Las diferencias estriban en que los padres homosexuales a) desafían estereotipos culturales que asumen que una mujer es necesaria para criar un/a niño/a y b) desarrollan estrategias para proteger a sus familias de un entorno hostil. En este artículo mostramos cómo un contexto heteronormativo que devalúa a la homosexualidad influye en las experiencias parentales de hombres gay en Chile. ${ }^{1}$

Palabras clave: Paternidad, paternidad gay, homoparentalidad, discriminación, gestación subrogada

\section{"I'm a normal dad": Parenting experiences of gay men in Chile}

Abstract: The identities of father and homosexual can be seen as mutually exclusive. The purpose of this paper is to explore how gay men in Chile experience parenting. In-depth interviews were conducted with fourteen men who self-identified as homosexual and had become fathers in a previous heterosexual relationship or 
with a same-sex partner (through gestational surrogacy or a co-parenting agreement). The results show that gay fatherhood is not essentially different from heterosexual fatherhood. Two main differences were identified: a) homosexual fathers challenge cultural stereotypes that assume that a woman is necessary to raise a child and b) they develop strategies to protect their families from a hostile social environment. A heteronormative context that devaluates homosexuality directly influences the parenting experiences of gay men in Chile. parenting.

Keywords: Fatherhood, gay fatherhood, discrimination, surrogacy, co-

\section{Eu sou um pai super "normal": experiências parentais de gays no Chile}

Resumo: As identidades de 'pai' e 'homossexual' tendem a ser vistas como mutuamente excludentes. O objetivo deste artigo é explorar as experiências de paternidade de homens homossexuais no Chile. Foram realizadas entrevistas em profundidade a 14 pais que se identificam como homossexuais ou gay e que tiveram filhos tanto no contexto de uma relação heterossexual, quanto no contexto de uma relação homossexual (através de barrigas de aluguel ou acordo de co-parentalidade). Os resultados mostram que a paternidade gay não é essencialmente diferente da paternidade heterossexual. As diferenças são que os pais homossexuais a) desafiam estereótipos culturais que pressupõem que uma mulher é necessária para criar um filho eb) desenvolvem estratégias para proteger suas famílias num ambiente hostil. Neste artigo, mostramos como um contexto heteronormativo que desvaloriza a homossexualidade influencia as experiências parentais de gays no Chile.

Palavras-chave: Paternidade, paternidade gay, homoparentalidade, discriminação, gravidez substituta

$* * *$

\section{Introducción}

Las identidades de 'padre' y 'homosexual' suelen verse como mutuamente excluyentes (Brown et al., 2009; Giesler 2012). Sin embargo, la paternidad por parte de parejas de hombres homosexuales ha aumentado en las últimas décadas. Cada vez más hombres gay ven a la paternidad como una etapa esperada de su trayectoria vital (Norton et al., 2013). A pesar de esta creciente tendencia, la investigación sobre los deseos, decisiones y experiencias de los padres gay es escasa. En comparación con los estudios realizados sobre maternidad lésbica (Lewin, 1993; Dunne, 2000; Donovan, 2000; Herrera, 2009), la paternidad gay ha sido sub representada. En los últimos años, este tema ha despertado el interés de los investigadores (Bos, 2010; Norton et al., 2013; Smietana, 2013 y 2016; Giesler, 2012; Berkowitz y Marsiglio, 2007). Se han estudiado las experiencias de transición a la paternidad a través de la gestación subrogada (Bergman et al., 2010; Smietana, 2013 y 2016), cómo estos padres negocian las expectativas de género (Giesler, 2012)y sus experiencias con sus identidades procreativas, paternales y familiares (Berkowitz y Marsiglio, 2007). También se ha comparado a familias compuestas por padres gay con otras configuraciones fami- 
liares (heterosexuales, lésbicas) para indagar aspectos como el bienestar de los padres y los niños y la calidad de la relación padre-hijo (Golombok et al., 2014; Bos, 2010). Todas estas investigaciones han sido llevadas a cabo en un contexto euroamericano. Son escasos los estudios que se han realizado en Chile y Latinoamérica (Laguna, 2016; Herrera, 2009).

El propósito de este artículo es explorar las experiencias de paternidad de hombres homosexuales en Chile. Más específicamente, analizamos cómo 14 padres gay han enfrentado la idea de la paternidad y la han ejercido en un contexto heteronormativo y, muchas veces, homofóbico. En Chile, la homoparentalidad $^{2}$ es un fenómeno incipiente. De acuerdo con los resultados de la encuesta CASEN 2015, un 6\% de las parejas del mismo sexo que conforman núcleos familiares, viven con los hijos de uno de sus miembros $^{3}$. Con este artículo queremos contribuir a una discusión más informada sobre la paternidad gay en Chile y Latinoamérica.

Chile ha recorrido un largo camino desde que, en el año 2004, la Corte Suprema le quitó la tuición de sus hijas a la Jueza Karen Atala argumentando que no podría criar a sus hijas en un entorno social apropiado ya que vivía con su pareja lésbica ${ }^{4}$. El año 2017,por primera vez la Corte Suprema otorga el cuidado personal de dos niños a un padre de orientación homosexual, estando en conocimiento que este convive con su pareja del mismo sexo. Esta sentencia es notable ya que falla a favor del interés superior de los niños reconociendo la situación de igualdad del padre y la madre (independientemente del género, el sexo o la orientación sexual) (Lathrop, 2017). Otra señal de apertura fue que el año 2015 se promulgó el Acuerdo de Unión Civil (AUC), el que puede ser suscrito por parejas del mismo sexo. Si bien esto es un avance importante, siguen quedando fuera los vínculos de filiación ${ }^{5} \mathrm{y}$, por lo tanto, las parejas del mismo sexo no tienen los mismos derechos que las parejas heterosexuales.

La opinión pública también ha tenido una evolución favorable hacia las parejas del mismo sexo en los últimos años. De acuerdo con la Encuesta CADEM (septiembre 2017) ${ }^{6}$, el 63\% de los encuestados cree que las parejas homosexuales tienen derecho a casarse (en febrero del 2014 la aprobación era del 50\%). No obstante, cuando se consulta por derechos de filiación, la aprobación baja al 43\% (en septiembre 2017). Esto es consistente con los resultados de la Encuesta CEP donde solo un 37\% de los chilenos cree que "una pareja del mismo sexo puede criar a un niño/a tan bien como una pareja heterosexual” (CEP, 2017, p.31). Mientras un 85,9\% de los habitantes de Santiago está de acuerdo con el uso de técnicas de reproducción asistida por parte de parejas heterosexuales (aun cuando no estén casadas) sólo un 26,6\% apoya el uso de estas técnicas por parte de parejas o personas homosexuales (Herrera, Teitelboim, Russo, Salas y Zegers Hochschild, 2013).

A pesar de los avances legislativos y al reconocimiento progresivo de la opinión pública de los derechos de las personas homosexuales, hay indicios de que la victimización y discriminación asociadas a la orientación sexual siguen siendo un problema en Chile. Los resultados del estudio 
realizado por Barrientos y Bozon (2014) con asistentes a la marcha de orgullo gay indican que el $73 \%$ de los hombres gay encuestados han percibido eventos de discriminación y el 82\% han sufrido eventos de victimización (burlas, insultos o amenazas). Los resultados de la Encuesta CASEN 2015 muestran que en el $45 \%$ de los hogares con jefe de hogar gay, lesbiana o bisexual, alguno de sus miembros ha sufrido discriminación en los últimos 12 meses (Ministerio de Desarrollo Social, 2016).La heterosexualidad es la norma y la homofobia sigue vigente. La desvalorización de la homosexualidad es internalizada por los jóvenes gay, dificultándoles construir una identidad positiva (Barrientos et al.,2016; Figueroa y Tasker, 2013).

En Chile, los hombres gay que han sido padres, ya sea producto de una relación heterosexual o con una pareja del mismo sexo, ejercen su paternidad en un contexto que devalúa su identidad sexual, los estigmatiza y discrimina. Asimismo, la legislación actual no les entrega protección legal a sus hijos/asal desconocer el vínculo de ambos padres con el niño/a. Esta falta de reconocimiento afecta cómo estos padres ejercen su paternidad.

\section{Metodología}

Los resultados expuestos en este artículo se basan en el análisis de una sub-muestra de un estudio cualitativo longitudinal sobre paternidad actualmente en curso ${ }^{7}$. Aquí consideramos los casos de padres que se auto identifican como homosexuales o gay, que han tenido hijos en el marco de una relación heterosexual o en el contexto de una relación homosexual (a través de gestación subrogada o acuerdo de coparentalidad).

Se realizaron entrevistas en profundidad con todos los participantes usando una pauta muy general y flexible de preguntas. El propósito de realizar entrevistas flexibles, sin una pauta rígida, es que tanto el/la entrevistador/a como los participantes puedan desarrollar temas inesperados y la entrevista siga la dirección que el entrevistado proponga (Deave y Johnson 2008; Herrera y Pavicevic 2016; Taylor y Bogdan, 1986).

Dado que intuíamos que el acceso a los participantes sería difícil, intentamos que los criterios de selección fueran simples: 1) auto identificarse como homosexual y 2) ser padre. Para contactar a los entrevistados, usamos nuestro círculo social, el método de bola de nieve -de modo que los entrevistados nos refirieran a otros padres gays- así como el contacto con organizaciones del movimiento LGBTI.

Los participantescorresponden a 14 padres que se auto identifican como hombres gay. Tienen entre 25 y 60 años (44 años en promedio) y, en su mayoría, residen en la ciudad de Santiago (2 de otras regiones). De los 14 participantes, tres son de otros países de Latinoamérica. Casi todos los participantes tienen educación universitaria (cuatro tienen postgrado, solo uno tiene educación media completa). Cinco fueron padres en un contexto homosexual,tres mediante gestación subrogada y dos a través de un arre- 
glo de coparentalidad. Los nueve restantes tuvieron hijos/as en el marco de una relación heterosexual. Seis entrevistados son católicos, uno es judío, uno ateo y seis manifestaron no tener religión. La edad de los/as hijos/as de los padres por una relación heterosexual está entre los seis y los 27 años. Los niños/as que nacieron en el marco de una relación homosexual tienen entre uno y siete años. Ocho de los padres conviven con alguno de sus hijos de manera permanente, dos tienen arreglos de custodia compartida con sus ex parejas mujeres y cuatro no conviven con sus hijos pero los visitan regularmente. Dentro de la muestra hay dos parejas de padres del mismo sexo. El nivel de ingresos de los hombres que tuvieron hijos con su pareja homosexual es significativamente más alto que el de los hombres que fueron padres en una relación heterosexual. Los altos costos de la subrogación y de la reproducción asistida en general hacen que sólo puedan acceder a ellas personas con altos recursos.

Las entrevistas fueron realizadas por los autores entre los años 2016 y 2017. Se realizaron en lugares públicos (como cafés) o en los hogares y lugares de trabajo de los entrevistados.Duraron un promedio de 90 minutos. En varios casos realizamosmás de una entrevista (el total fue de 21 entrevistas). Estas fueron grabadas, transcritas y analizadas por los autores del artículo ${ }^{8}$.

Los resultados que presentamos corresponden a un análisis de las entrevistas realizadas a padres gays, en el marco del proyecto general.La información recopilada en las entrevistas fue analizada utilizando análisis de contenido temático, que consiste en la "descomposición o fragmentación del texto en unidades constitutivas para su posterior codificación" (Ruiz, 2009, p. 8). Utilizamos un sistema mixto de categorías, algunas fueron creadas de manera previa a la lectura de las transcripciones (categorías a priori) y otras mientras se leían las transcripciones de las entrevistas (categorías emergentes).

Esta investigación fue aprobada por el Comité de Ética de la Universidad Diego Portales. Los investigadores nos comprometimos a que la participación fuera informada y voluntaria. Protegemos la identidad de los participantes mediante el uso de seudónimos para ellos y su círculo cercano, y no revelamos información que pudiera permitir su identificación. Considerando que en Chilela paternidad gay es un tema aún cuestionado y mediático, probablemente los participantes no habrían accedido a ser entrevistados sin estos resguardos. Todos los participantes firmaron un consentimiento informado donde se explican los propósitos del estudio y las condiciones de su participación.

\section{'Siempre quise tener hijos': conciencia procreativa en hombres gay}

Se suele suponer que si un hombre es homosexual, entonces no es padre. Estas dos identidades se consideran incompatibles. La exclusión de 
los hombres gay de la paternidad puede explicarse por varias razones: 1) Las relaciones sexo-afectivas entre hombres no dan 'naturalmente' paso al engendramiento. Así, a una pareja gay le es imposible calzar con nuestro paradigma de parentescooccidental, en el que la pareja de padres (progenitores) es la misma que la pareja conyugal (Cadoret, 2003; Herrera, 2009). La paternidad gay requiere una planificación consciente y evaluación de opciones, además de un ‘otro facilitador' (Norton et al. 2013). Todos los caminos para convertirse en padres -coparentalidad, adopción, subrogaciónimplican ser creativos y superar importantes barreras culturales. Lalegislación chilena vigente les dificulta aún más el acceso a la paternidad. La vía heterosexual aparece como la más sencilla y factible. De esta forma, muchos hombres gay priorizan su deseo de tener hijos y formar una familia 'congelando’ sus deseos homoeróticos (Laguna, 2013).

2) Mientras los hombres heterosexuales legitiman su posición como padres por 'derecho natural' (Haces, 2006), los hombres gay viven en entornos sociales heteronormativos que devalúan lo homosexual y desvalorizan sus capacidades para ser padres (Laguna, 2016). La homosexualidad continúa siendo erróneamente asociada a conductas sociales incompatibles con la paternidad, como la perversión sexual y la pedofilia. Berkowitz y Marsiglio (2007) sostienen que el ser socializado en un mundo que asocia la homosexualidad masculina con la pedofilia evita que los hombres gay se visibilicen a sí mismos como padres.

3) La paternidad gay choca con prácticas de género profundamente enraizadas en nuestra cultura que asumen que las tareas de cuidado y crianza son esencialmente femeninas (Miller, 2011; Bergman et al., 2010). En el ámbito reproductivo, los hombres aparecen como personajes secundarios (Dolan y Coe, 2011; Herrera, 2013). Los padres gay transgreden una norma social implícita: las mujeres, no los hombres, deben ser las cuidadoras primarias de los niños/as (Stacey, 2006; Giesler 2012). De esta forma, los padres gay no solo sienten que están luchando contra los estereotipos homosexuales, sino también contra las nociones culturales que feminizan el cuidado de los/as hijos/as.

Estos aspectos son internalizados por los hombres gay a tal punto que muchos consideran su identidad sexual como incompatible con la paternidad (Bergman et al. 2010). Berkowitz y Marsiglio (2007) utilizan el concepto de 'conciencia procreativa' para referirse a la conciencia que tienen los hombres gay respecto a sus propias capacidades reproductivas. Los autores argumentan que esta conciencia evoluciona a lo largo de la vida y está influenciada por factores externos, como por ejemplo, un contexto social que devalúa la homosexualidad y privilegia la paternidad heterosexual. Los resultados de su estudio cualitativo realizado en EEUU señalan que muchos hombres gay asumen automáticamente que la paternidad no es una opción para ellos: ser gay equivale a no tener hijos. El proceso de 'salir del clóset', en términos de asumir una identidad homosexual, se vinculaa el proceso de asumir que nunca serán padres (Smietana, 2013; Murphy, 2013). Para algunos, la parte más difícil de asumir una identidad homosexual es renunciar a la paternidad (Giesler, 2012). 
Coincidentemente, la mayoría de los participantes de este estudio pensaron que si se asumían como hombres gay jamás serían padres. Tener hijos fue para muchos un proyecto anhelado desde la infancia. Dejar de lado este proyecto fue uno de los aspectos más dolorosos de asumir su orientación sexual. Mateo, al inicio de la primera entrevista, relata cómo, para él, ser padre siempre fue una aspiración:

Yo creo que el deseo de ser padre lo tengo desde que estoy muy chico, yo fui hijo único (...) mi mama siempre decía 'a tener muchos hijos, yo no quiero que seas hijo único’ y después a la medida que iba creciendo, iba creciendo, y ya llegaba a ser adolescente y me iba... me había dado cuenta que era gay era... era un tema súper complejo porque sentía que si me aceptaba como gay estaba renunciando a mi necesidad de ser padre, entonces era una contradicción y una lucha de... de necesidades, por un lado quería tener la libertad de ser yo mismo, pero por otro lado también quería ser papá, entonces decía si me acepto... el momento que me acepte renuncio a ser papá, porque no va a ser fácil(Mateo, padre en contexto homosexual por acuerdo de coparentalidad).

Incluso hoy, para varios entrevistados que tuvieron hijos en el marco de una relación heterosexual, la paternidad habiendo 'salido del clóset' se ve como algo imposible. A Víctor y Sergio, ambos padres producto de una relación heterosexual, la entrevistadora les preguntó si siempre había estado en sus planes ser padres. Los dos responden afirmativamente, y luego señalan que cuando jóvenes no estaban conscientes o no habían asumido su homosexualidad. En sus palabras podemos apreciar que asumir una identidad homosexual les hubiera impedido ser padres. Víctor señala: "Siempre, desde chico siempre quise ser papá. Es que cuando yo era chico ehh... yo creo que en algún lugar de mi inconsciente siempre supe que era gay, pero nunca quise experimentarlo ni asumirlo cachai” (Víctor, padre en contexto heterosexual). Por su parte, Sergio sostiene:

Sí, siempre [estuvo en mis planes tener hijos]. Siempre, siempre, porque yo no tenía asumido mi homosexualidad para nada, yo pensé que era una tontera de cabro, que era como un desvío mío, que no era algo real para nada, pero después de casado, estando casado emmm, al separarme, me di cuenta que sí, pero siempre estuvo en mis planes ser papá, siempre (Sergio, padre en contexto heterosexual).

Algunos entrevistados simplemente siguieron el camino trazado delante de ellos por las expectativas heteronormativas que les imponía su entorno. En algunos casos fue una paternidad no planificada. Antonio, por ejemplo, relata que tuvo a su hijo mayor 'por accidente' cuando tenía 15 años. Para Andrés, la paternidad fue 'algo natural', una de las etapas que se deben cumplir en la vida:

[Tener hijos] era parte de la vida, además de que yo era una persona tremendamente estructurada y en la vida me habían enseñado que tu 
naces, creces, vas al colegio, entras a la universidad, te casas, tienes hijos, casa, perro, y yo estaba muy [ademán con las manos señalando que él estaba muy concientizado con ello] (Andrés, padre en contexto heterosexual).

Cuando los padres que han tenido hijos en el marco de una relación heterosexual se plantean la paternidad en un contexto homosexual la ven como un proyecto lleno de obstáculos. Esta es la respuesta de Aníbal cuando el entrevistador le pregunta si ha pensado en tener más hijos:

O sea, eh, igual ahora es más difícil po’ cachai, yo soy gay po’ cachai, entonces tengo parejas hombres po’ cachai. Entonces el tema de la paternidad igual no es que se descarte cachai, porque quizás hay formas de ser papá igual cachai de... es más complejo cachai, no es tan... (...) a la biología le tenis que poner una parte de tecnología, de cachai, de voluntad, otras cosas cachai (Aníbal, padre en contexto heterosexual).

Aníbal considera que es más difícil ser padre ya habiendo salido del clóset y teniendo parejas hombres. Aquí la paternidad heterosexual aparece como algo fácil, sin complicaciones extra, aludiendo al modelo de parentalidad biológica, donde un hombre y una mujer tienen relaciones sexuales y se engendra un hijo (Cadoret, 2003). Mientras que a la paternidad homosexual hay que sumarle 'la tecnología' y 'la voluntad'. Suponemos que aquí está haciendo alusión a la imposibilidad de que dos hombres engendren un hijo y a la posibilidad de acudir a las técnicas de reproducción asistida (como la gestación subrogada). Es interesante que mencione a 'la voluntad' como uno de los aspectos que se deben sumar, dando por hecho que esta no estaría tan presente en la paternidad heterosexual. Los hijos, en la paternidad heterosexual biológica, vendrían por si solos. Y en la paternidad homosexual se deben buscar activamente, acudiendo a la tecnología.

En la segunda entrevista a Víctor reaparece la idea de la dificultad de ser padre habiendo asumido una identidad homosexual. La homoparentalidad surge como un proyecto casi imposible de alcanzar. Víctor no está tan equivocado. Todos los participantes de este estudio que han tenido hijos en el marco de una relación homosexual han seguido procesos largos y costosos, varios de ellos fuera de Chile. Víctor sostiene que, al ser imposible adoptar en Chile, hay que hacerlo en el extranjero, y esto lo vuelve aún más caro y difícil.

Pero yo creo que tampoco están tan dadas las condiciones cuando asumes la homosexualidad de forma temprana para tener un hijo, es un proceso complejo, caro, porque tanto si adoptas o si haces todo el sistema de ambas formas, porque no puedes adoptar en Chile, tienes que adoptar en otro país, entonces no, no sé si hubiera sido padre en concreto, bajo ese punto de vista (Víctor, padre en contexto heterosexual). 
Inicialmente, para los hombres gay que desean ser padres, la única alternativa que les parece factible es la de seguir el camino heteronormativo y llevar una 'doble vida', adentro del clóset. Mateo, padre de dos niños por un acuerdo de coparentalidad, pensó que la única forma de alcanzar la paternidad era casarse con una mujer.

Después ehhh aparte era como que decía 'listo, ¿`sabe qué? me voy a casar voy a tener mis hijos y voy a olvidarme de ser gay' pero después decía 'nooo, es algo imposible, doble vida, pucha vivir con engaños, engañar a mi señora engañar a mis hijos a todo el mundo no, no, no' (Mateo, padre en contexto homosexual por acuerdo de coparentalidad).

En la primera entrevista a Humberto, antes del nacimiento de su hijo por gestación subrogada, él señala que pensó en tener una relación amorosa con una mujer sólo para tener hijos. Al igual que Mateo, descartó esta opción pues le pareció 'poco honesta'. Su segunda opción fue la adopción, pero rápidamente se informó que en Chile era imposible adoptar como hombre gay. Sólo cuando supo que existía la gestación subrogada pensó que podía ser padre.

El proceso de la paternidad para mí ha sido muy largo y... en algún momento pensé yo que no... no había para mí una posibilidad de ser padre, lo pensé digamos gran parte de mi vida activa, hasta que de repente me enteré de la posibilidad de la... subrogación (Humberto, padre en contexto homosexual, por gestación subrogada).

Berkowitz y Marsiglio (2007) se preguntan cómo los hombres gay toman conciencia de sus posibilidades reproductivas. En el caso de los participantes, la paternidad continúa fuertemente asociada a la heterosexualidad. Asumir una identidad homosexual daña su capacidad reproductiva. Intentan imaginar caminos para tener hijos fuera del marco heterosexual. Piensan en la adopción, pero la descartan porque les parece imposible. La gestación subrogada sólo es alcanzable para un grupo pequeño, que cuenta con los recursos y la energía para llevarla a cabo.

\section{"El que yo sea gay no cambia nada": experiencias parentales de hombres homosexuales}

La paternidad es desafiante tanto para hombres homosexuales como heterosexuales. En su estudio en EEUU,Bergman et al. (2010) señalan que la experiencia de transición a la paternidad de los padres gay era, en muchos sentidos, similar a la de padres heterosexuales en diversas estructuras familiares. Todos comparten las experiencias de equilibrar las responsabilidades laborales con las de la crianza, de buscar apoyo en familiares y amigos y de sentirse orgullosos en su nuevo rol de padres. Bos (2010), compara las relaciones padre - hijo, las experiencias parentales de estrés y el bienestar 
psicológico de los hijos en padres heterosexuales y gay,concluyendo que estos padres tienen mucho en común.

Estas similitudes no deberían sorprendernos ya que el ejercicio de la paternidad no tiene por qué estar vinculado a la orientación sexual de los padres. Al igual que muchos padres heterosexuales (Herrera y Pavicevic, 2016), los padres gay de este estudio pueden adscribirse al modelo de 'nueva’ paternidad o ‘paternidad involucrada' (Olavarría, 2001a y 2001b; Valdés 2008 y 2009; Miller, 2011) ya que quieren ser padres cariñosos y cercanos. Cuando se les pregunta si ser un hombre homosexual marca alguna diferencia en su ejercicio de la paternidad, varios contestan negativamente. Por ejemplo, Octavio responde:

Yo creo que hay muchas diferencias de ser padre, pero están ligadas a tus características de persona, no de tu opción sexual, sino, eres una persona más empática, menos empática, más racional, más emotiva, las características de tu personalidad son las que condicionan el tipo de paternidad que vas a terminar teniendo (Octavio, padre en contexto homosexual por acuerdo de coparentalidad).

Algunos participantes piensan que tener un padre gay es beneficioso para sus hijos, ya que esto los hace más abiertos y tolerantes. Les enseña a valorar la diversidad. Esto es coherente con los resultados de Giesler (2012), donde los participantes destacan en sus hijos cualidades como la sensibilidad, apertura y tolerancia, adjudicándolas al hecho de haberse criado en una familia homosexual. Antonio opina:
Al ser homosexual lo único que ha significado para mis hijos es sumar cosas buenas. En el sentido de que ellos han sido privilegia- dos en darse cuenta cómo vive una pareja homosexual, cómo vive como pareja, cómo funciona, cómo papá y son premiados en ese sentido porque a ellos les da una amplitud de diversidad ¿cachai? Entonces cuando ellos se encuentran con parejas así... no sé si me entendí, pero ellos como... pa' ellos es tan normal (risas) es que para nosotros es súper normal lo que vivimos ¿cachai? (Antonio, padre en contexto heterosexual).

Estos padres no argumentan que el hecho de que sus hijos sean más tolerantes y valoren la diversidad, se derive directamentede su orientación sexual. Más bien, esto sería efectode crecer en una familia 'diferente', que desafía al entorno heteronormativo. Podríamos pensar que el mismo efecto se lograría con padres migrantes, o padres con discapacidad. Es decir, lo que llevaría a que los hijos valoren la diversidad como algo positivo es creceren familias que rompen con distintas expectativas sociales, o cuyas identidades son desvalorizadas socialmente.

De acuerdo con Berkowitz y Marsiglio (2007), los padres gay se preocupan de cómo su propia homosexualidad puede afectar negativamente la vida de sus hijos. Algunos padres de este estudio consideran que su 
orientación sexual ha perjudicado a sus niños. Esto es más común entre los entrevistados que han sido padres producto de una relación heterosexual. Rafael se cuestiona por qué se siente culpable:

Yo creo que los gays somos un poquito culposos y que ese es un tema súper heavy, entonces como que tu tenis que compensar por ser gay, y siempre tienes que dar algo por ser gay, eso es parte de la esencia del ser gay, hasta que tu sientes que hay una cosa de asumido en que te preguntas ¿por qué tengo que estar pagando?, ¿por qué tengo que tratar de llevar a todo el mundo de viaje si soy normal? (Rafael, padre en contexto heterosexual).

Por otro lado, Andrés no cree que su orientación sexual haya tenido una influencia en su manera de ser padre. Sin embargo, sí piensa que al 'salir del clóset' les hizo daño a sus hijos. Sostiene que si 'volviera la vida atrás, no tendría hijos', para evitarles 'ese daño'. En los casos de Antonio y Andrés tampoco es la orientación sexual por sí misma la que marca la experiencia de la paternidad. Es el entorno social que estigmatiza el ejercicio de la paternidad por parte de hombres homosexuales el que tendría mayor impacto. Sus culpas y arrepentimientos pueden explicarse, al menos en parte, por la homofobia internalizada (Barrientos et al. 2016).

Entonces, si bien los padres gay tienen bastante en común con los padres heterosexuales, se diferencian de ellos al vivir en un entorno social que desvaloriza su identidad sexual y estigmatiza su ejercicio parental (Bergman et al., 2010). Los resultados del estudio de Bos (2010) indican que los padres gay se ven afectados por las experiencias de rechazo y sienten que deben estar continuamente defendiendo su rol de padres. No es necesario haber experimentado directamente el rechazo y la discriminación para sentir sus efectos. Brown et al. (2009) señalan que un porcentaje relevante de sus participantes viven con miedo y están siempre esperando ese 'encuentro homofóbico'. Existe una 'discriminación anticipada', donde los padres gay piensan que sus hijos sufrirán discriminación en el futuro.

Uno de los principales miedos de los padres es que sus hijos sufran 'por su culpa'. Gonzalo, padre mediante una relación heterosexual,dice que teme que a su hijo le hagan daño por tener un padre gay. Sergio sostiene: "Me costó asumirlo [ser gay], tenía que ver con el cómo iban a hacerle bullying a mi hijo el día de mañana” (padre en contexto heterosexual). La mayoría de los participantes en este estudio han sufrido experiencias discriminatorias relacionadas con su paternidad. Víctor explica que él se ha sentido cuestionado por ser un padre gay:

Yo siento que estamos en un país que rechaza esta condición o conducta que yo estoy teniendo en la vida, que no la comprende, y yo creo que indirectamente sí me he sentido rechazado, sobre todo por un ambiente más conservador, más ABC1, más católico, sí me he sentido como desplazado (...) Entonces, sí, emmm, siento que sí hemos sentido momentos de rechazo o de cuestionamiento por nues- 
tra labor como padres siendo gays, sí, pero ninguno de esos rechazos a mí me ha opacado (Víctor, padre en contexto heterosexual).

En el caso de quienes fueron padres en el marco de una relación heterosexual, el 'salir del clóset' agrega una dimensión extra de preocupación para sus familias. Las familias suelen preocuparse del impacto que tendrá en los hijos la orientación sexual del padre (Berkowitz y Marsiglio, 2007). Al respecto Alex sostiene que cuando decidió asumir su identidad homosexual se dio cuenta que el principal problema no era cómo lo iba a tomar su hijo, si no su familia:

Sí, y bueno, ahí me di cuenta que el problema no era él [su hijo], cómo lo ibaa enfrentar, era yo, como yo lo iba a enfrentar frente a él y frente a todas las personas y mi familia, mi familia sabe, siempre supo, pero no hubo apoyo, ahí hubo prejuicio 'pucha estai criando a un niño ¿Qué le vai a enseñar, que le vai a mostrar?’ (Alex, padre en contexto heterosexual).

Los cuestionamientos hacia la paternidad gay alcanzan niveles extremos cuando los prejuicios asocian homosexualidad con pedofilia. Varios participantes aluden a acusaciones de abuso sexual, a ellos o a sus parejas. Rafael relata como su hermano insinuó que su pareja podría haber abusado de su hijo:

Deben pensar 'pobre Maxito, lo que le tocó vivir, podre niñito, debe estar trancado’. Es más, las cosas por la que una vez me pelié con mi hermano fue que osó intentar decirme que si acaso Max había sido abusado por mi pareja. Y ahí yo le dije 'tú, no me puedes decir eso, porque yo tampoco sé si tu mujer ha abusado de Max cuando ha estado en tu casa'. Entonces, eso, prejuicios horribles, claro (Rafael, padre en contexto heterosexual).

Los padres que tuvieron asus hijos en contexto homosexual sufrieron graves problemas legales en el camino para alcanzar la paternidad o en el ejercicio de esta. Estos obstáculos han sido interpuestos por funcionarios o familiares con ideas homofóbicas ${ }^{9}$. Estas situaciones de discriminación -relacionadas con su orientación sexual y con su género- han puesto en entredicho el derecho de estos hombres a ser padres. Aquí la madre aparece como una figura central. Como señalan Bergman et al. (2010), uno de los obstáculos que enfrentan los padres gay tiene relación con el desafiar estereotipos culturales que asumen que para una crianza sana es necesaria la presencia de una madre. En los casos de gestación subrogada, la falta de una madre hace que se cuestione que los padres (dos hombres) sean capaces de cuidar adecuadamente a los hijos (especialmente si estos son pequeños). En los casos de coparentalidad se asume que el cuidado de los hijos será realizado por la madre. El reconocimiento legal de los vínculos de filiación es crucial para el reconocimiento social (Hequembourg y Farrell, 1999). Los padres que no tienen un vínculo legal con los hijos son los más perjudicados ya que esto lleva a que su relación con sus niños no sea 
reconocida en otros ámbitos. Octavio relata cómo el establecimiento educacional de sus hijos no dejaba entrar a su pareja, quien también es padre de los niños. El problema es que sólo Octavio es el padre legal:

\begin{abstract}
'Mira no creo que las leyes del instituto contradigan las leyes de educación y según la ley de educación yo tengo derecho... presenciar toda la reunión' y obviamente me solicita que la reunión tiene que ser a solas, que Mateo no puede asistir porqueno es padre legal. Mateo no pudo entrar conmigo al salón para el día del padre, ella [la madre] pudo entrar con acompañante sin problemas el día de la madre, pero yo no podía tener un acompañante el día del padre (Octavio, padre en contexto homosexual por acuerdo de coparentalidad).
\end{abstract}

Los padres que han alcanzado la paternidad en el contexto de una relación heterosexual y aquellos que la han alcanzado en el marco de una relación homosexual se enfrentan a desafíos un poco diferentes (rol que cumple la figura materna -si existe-, vínculos legales de filiación del segundo padre). Sin embargo, la experiencia parental de todos se ve marcada por las implicancias de vivir en un entorno heteronormativo y, muchas veces, homofóbico.

\title{
'No quiero mostrarle un mundo hostil': Estrategias de protección
}

Cómo señalábamos en el apartado anterior, si bien la experiencia de los padres gay es, en muchos aspectos, muy similar a la de los padres heterosexuales, hay un aspecto que los diferencia: la posibilidad de que sus familias sufran discriminación. Bozett (1980), quién hizo entrevistas a padres gay que habían tenido hijos producto de relaciones heterosexuales en EEUU, sostiene que sus entrevistados intentan proteger a sus hijos de la hostilidad. Y la primera estrategia que ocupan es la discreción. Por ejemplo, evitar demostraciones públicas de afecto y no andar con 'la pancarta' gay. Laguna (2013), que hizo trabajo de campo con hombres homosexuales que se habían convertido en padres a raíz de relaciones heterosexuales en México, señala que los hombres desarrollan mecanismos para proteger a sus hijos de las implicancias de tener un padre homosexual. El autor denomina a estos mecanismos 'burbujas de seguridad', 'escudos' o 'círculos de protección’.Laguna sostiene:

Por otra parte, aunque las necesidades de los hijos e hijas de los padres gay no son distintas a aquellas de hijos de parejas heterosexuales; ellos deben prever los posibles problemas que podrían afrontar el niño o la niña y dar soluciones antes de que afecten su bienestar. De ahí que no dejan al azar la educación de los hijos ni permiten que los controles heteronormativos les afecten; por ello, requieren implementar prácticas que impidan que la homofobia perturbe a los infantes. Un elemento primordial de las prácticas de cui- 
dado de los hijos de los padres gay es su protección, por ello buscan que ningún fenómeno externo les pueda afectar. A partir de lo cual desarrollan diversas estrategias para protegerlos (2016, pp. 197 198).

Los hombres gay son conscientes del daño que puede producir la homofobia. Y esto les lleva a realizar adaptaciones en su ejercicio del cuidado parental. Algunas de las estrategias de protección que identifica Laguna (2016) en sus entrevistados son: a) mantener una estrecha comunicación con sus hijos, b) crear un secreto, c) proveer de educación sexual y de género. Según el autor,la segunda estrategia es utilizada por padres que no tienen los elementos para crear entornos seguros para sus hijos. Así, el mantener la orientación sexual del padre como un secreto permite proteger a la familia de un entorno social hostil. En contextos sociales menos hostiles, como el español, los padres homosexuales son abiertos son abiertos respecto a su composición familiar y su orientación sexual (Smietana, 2016).

Todos los participantes de este estudio desarrollan estrategias para reducir las posibilidades de que se produzcan eventos discriminatorios en las vidas de sus hijos. Todos consideran que es su deber proteger a sus hijos/as y anticiparse a cualquier experiencia de rechazo. Las medidas que toman para proteger a los niños/as adquieren diferentes formas, y algunas parecen contradictorias. Estas medidas podrían organizarse en torno a dos polos: de cierre y de apertura. Algunos padres se posicionan más cerca de uno de estos polos, pero la mayoría combina estrategias de apertura con estrategias de cierre o ‘no exposición’.

Brown et al. (2009) llaman la atención sobre cómo los padres y madres homosexuales deben tomar decisiones sobre cuándo, a quién y cómo revelar u ocultar su orientación sexual. Asimismo, sienten que continuamente deben explicar su estructura familiar a otros. Estos ‘otros' pueden ser vecinos, personas de establecimientos educacionales, personal de salud o simples extraños en la calle. Preguntas como ‘¿Dónde está la mamá?’ O ‘¿Quién es el padre?’, son comunes. En un entorno en que la homosexualidad está estigmatizada, el manejo de la privacidad y la seguridad es un proceso constante para los padres no heterosexuales. La decisión de ser 'abiertos’ o ‘cerrados' dependerá de la facilidad para explicar el arreglo familiar y del contexto particular.

Varios participantes mantienen oculta su orientación sexual en, al menos, algunos ámbitos de su vida: el trabajo, el colegio de sus hijos, su entorno social menos cercano. Su experiencia como padres no los ha llevado a pensar que deben ser más abiertos, todo lo contrario, estiman que 'el secreto’ (Laguna, 2016) es la mejor manera de proteger a sus hijos. Alex ha optado por mantener oculta su identidad homosexual. Su hijo estaba en un colegio católico y, de acuerdo con Alex, “se enteraron de mi sexualidad”, y comenzaron a "hacerle preguntas y aislarlo”, por lo que decidió cambiarlo de colegio. Esta experiencia reforzó la convicción de Alex de que la mejor estrategia para proteger a su hijo es el 'clóset': 
Yo siempre preferí callar, porque preferí que hablaran de mí que de mi hijo, porque si le contaba a algún adulto ‘sabes que soy gay' con un hijo o una hija, le va a contar a otras personas y al final se va a formar una red y esa red tarde o temprano iba a llegar a mi hijo. Por ejemplo, ahora en el colegio no saben, no sospechan tampoco, pero si una persona supiera, le va a contar a su hijo y su hijo le va a contar a sus compañeros y ya va a ser bullying contra él 'puchaa tu papá es gay' (Alex, padre en contexto heterosexual).

En el caso de Sergio, solo sus cercanos y familiares conocen su orientación sexual. Este es un aspecto que prefiere mantener oculto en su ambiente laboral. En la siguiente cita vemos que le pide a su hija que no revele su homosexualidad a sus amigas. Para él, esta es una medida de protección para evitar que ella sufra algún tipo de rechazo del que luego podría responsabilizarlo:

Lo que yo me preocupaba en decirle 'hija tú no le cuentes a tus amigas lo que yo soy, si tus amigas son relajadas y les quieres contar, háblales', eso se me hizo complejo a mi porque yo no quería que ella saliera dañada y que un día me dijera “ipor tu culpa...! (Sergio, papá en contexto heterosexual).

Tanto Alex como Sergio han tenido hijos en el marco de una relación heterosexual. De acuerdo con sus palabras, lo que están ocultando es su propia identidad sexual. En el caso de Humberto, que ha sido padre en el marco de una relación homosexual, ha optado por ocultar no sólo su homosexualidad si no también la historia de cómo llegó a convertirse en padre. En la primera entrevista que se le realizó, antes del nacimiento de su hijo, Humberto relata que ha decidido contar que es papá soltero. Presenta esta decisión como una medida para proteger a su futuro hijo:

A las otras personas les conté una historia que es mucho más cómoda en realidad, que es la historia del hombre que embaraza a una mujer y decide hacerse cargo (...) sí, entre más privado sea esto, más familiar, es más protección, no pa’ uno, uno ya las ha pasado todas, sino que es por el bebé que va a un colegio, que va a un jardín, que la sociedad y tiene que enfrentarse con sus cosas. Y ahí uno va a estar pa' defenderlo, pa’ protegerlo, pa’ hacerle cariñito (Humberto, padre en contexto homosexual por gestación subrogada).

En la tercera entrevista, cuando su hijo ya tiene un año, Humberto se mantiene firme en su decisión. El niño le dice ‘tío’ a la pareja de Humberto. Como es pequeño, aún no han tenido que enfrentar cómo le explicarán a él su historia y su configuración familiar.

Y yo encuentro que es más cómodo pa' él también, pa' todo el mundo en realidad, cuando uno ve cosas así sociales, son como de mucha discriminación y con mucho desconocimiento, entonces too' me refiero inmediatamente en eso que es lo mejor, pensando en colegio, 
pensando que ahora se viene el bautizo, lo queremos bautizar no sabemos cómo nos irá con eso (...) es suficiente, digamos, no es necesario plantearse con más violencia, como dijera yo, encarar a la gente de otra manera (...) para un niño que está empezando su experiencia puede ser muy doloroso, muy incómodo (Humberto, padre en contexto homosexual por gestación subrogada).

La asociación entre homosexualidad masculina y pedofilia puede poner a los padres gay en una situación muy delicada. Para protegerse a ellos mismos y a sus hijos se restan de realizar tareas cotidianas de cuidado que puedan resultar 'sospechosas' para miradas externas. Por ejemplo, Alex sostiene que él prefiere no bañar a su hijo pequeño. Este es un buen ejemplo de cómo la homofobia puede afectar el desarrollo de la paternidad.

Pero ¿qué es lo que pasa? si viene él y dice 'mi papá me estaba bañando', 'ahh que lindo tu papá te estaba bañando...' 'pero tu papa es gay y te estaba bañando’, y es como ‘y la pareja de tu papá ¿estaba ahí también?’, entonces empiezan las preguntas y es algo que no lo veo mal a mí en lo personal, me gustaría bañarlo, decirle que tiene un pirulin, no sé po, lo que hace un papá normal, sin una maldad detrás, pero uno no sabe lo que puede decir con toda inocencia 'mi papa y su pareja' o en algún momento su marido (Alex, papá en contexto heterosexual).

Las estrategias de cierre y de apertura no son excluyentes. Algunos padres deciden ser abiertos respecto a su identidad sexual para ahorrarles a sus hijos tener que dar explicaciones, pero, al mismo tiempo evitan invitar a amigos de sus hijos a su casa. Por ejemplo, Rafael, habló con el profesor de su hijo en el colegio:

También cuando llegué al colegio hablé con el profesor de Max y dejé las cosas 'aquí yo soygay, estoy con mi pareja, no quiero tener problemas en el colegio, pero tampoco quiero que en el colegio no sepa y si hay cosas, yo voy a venir con mi pareja', nada de andar a escondidas... Por eso yo creo que el desafío ha sido como mostrar que no somos bichos raros, y que podemos ser papás, y que podamos tener un hijo que es amado que está feliz y que puede tener tantas trancas como los hijos de papás heterosexuales (Rafael, papá en contexto heterosexual).

Sin embargo, el mismo Rafael sostiene que para evitar situaciones potencialmente incómodas para su hijo, prefiere que las reuniones sociales con sus amigos se realicen en la casa de la madre.

Hoy en día tengo más cuidado en hacer cosas y organizar algunos planes que si fuera hetero, no se me pasarían por la cabeza, como en el cumpleaños del Max 'hagamos un asado, entretenido, invita a tus amigos, yaa, hagámoslo en la casa de la Vero’ [ex mujer], jamás se me pasaría hacerlo en mi casa para no exponerlo a él, cachai. Entonces 
sí, eso sí, he tenido que tener más cuidado en ese tipo de cosas. ¿Ponerlo en esa situación pa’ qué? ¿Pa’ decir que soy gay y me da lo mismo?, no, no, yo no utilizo a mi hijo para mi destape homosexual, estamos en Chile, no en otra parte. (Rafael, papá en contexto heterosexual).

Cuando Rafael señala 'estamos en Chile, no en otra parte' revela que está muy consciente del entorno social. Percibe que este es un entorno conservador y homofóbico. Y desarrolla estrategias para minimizar las posibilidades de que su hijo se enfrente a este ambiente hostil. Para proteger a los hijos se puede, por un lado, ser abierto con respecto a la identidad homosexual y a la relación de pareja y, por otro, resguardar la privacidad. Rodolfo señala que él es muy selectivo con respecto a quién deja entrar en la intimidad de su hogar:

Y tengo cuidado por ejemplo de la empleada del servicio que venga, o del que me venga a mi casa, tengo un poquito de cuidado quién es el que viene porque yo no quiero estar en boca de nadie, de que ‘estos maricones que tienen esos niños gringuitos’ (Rodolfo, padre en contexto homosexual, por gestación subrogada).

En el proceso de manejar cuándo ser abiertos y cuándo proteger su privacidad, varios padres señalan el peligro de la sobre exposición. Sostienen, como Rafael, que no quieren usar a sus hijos para 'su destape homosexual'. Unos cuantos entrevistados han rechazado ofertas de salir en programas de televisión. Ellos argumentan que no quieren someter a sus hijos al escrutinio público. Asimismo, varios padres sostienen que hay que distinguir cuando vale la pena explicar la configuración familiar y cuando no. Para la mayoría, no vale la pena dar explicaciones a extraños en lugares públicos. Rodolfo afirma que en ocasiones prefiere no sacar a las personas de su error cuando éstas ya se han hecho una idea de cuál es el vínculo que lo une a sus hijos:

No a ponerme letreros ni a exponerme, y a exponerme mucho y en situaciones que uno sabe que no vale la pena. Entonces... hay situaciones que uno está con los niños, ay qué usted, que tan lindo, ‘¿usted es el abuelito?', 'Sí, yo soy el abuelito’. Si me entiendes, yo no tengo por qué dar explicaciones ni nada (Rodolfo, padre en contexto homosexual por gestación subrogada).

En la misma línea, Florencio señala que él y su pareja han tenido que reflexionar sobre cómo responder a la clásica pregunta hecha por desconocidos en lugares públicos: ‘¿dónde está la mamá?’ Esta pregunta refleja la extrañeza de las personas al ver a un bebé con dos hombres y sin ninguna mujer cerca. No es una imagen que los espectadores codifiquen como una familia. Florencio y su pareja han optado por no explicar su configuración familiar. La respuesta que les da Florencio es tranquilizante ya que implica que sí existiría una mujer que está a cargo del cuidado de ese bebé: 
Yo creo que cuando era más chiquitita, hace tres cuatro meses atrás, cuando salíamos, siempre preguntaban por la mamá. Entonces nos sentamos y dijimos tenemos que tener una respuesta pa' eso. Tenemos que empezar a tener una respuesta nosotros para cuando pregunte ella cachai. Y yo creo que esa va a ser una pega bien importante, pero ahora yo digo 'no, se quedó en la casa haciendo empanas' cualquier cosa o 'noo, anda de viaje’, 'ayy, sí que bueno’ [imitando a la gente responder], cualquier cosa (Florencio, padre en contexto heterosexual y homosexual).

Así como para algunos padres, proteger a sus hijos pasa por mantener oculta su identidad sexual, para otros, el proteger a los hijos es sinónimo de ser abiertos. Este suele ser el caso de los hombres que se han convertido en padres con una pareja del mismo sexo. Para ellos, al mantener un secreto estarían comunicándoles a sus hijos que la homosexualidad es algo negativo. En palabras de Mateo: "no queremos a los niños darles a entender un mensaje erróneo de que es algo malo... porque si tú le dices oculta esto, estás diciendo algo malo, entonces estas diciendo 'tu papá tiene algo malo'... y no es así....” (Mateo, padre en contexto homosexual). Para Octavio ser padre es sinónimo de estar totalmente fuera del clóset. Y esto no sólo se refiere a su orientación sexual, sino también a la naturaleza amorosa de la relación de los padres y a su configuración familiar.

Tengo que proteger a mis hijos... y lo que yo siento que no puedo hacer de ninguna forma es trasmitirle a mis hijos que en mi familia hay algo mal, que hay algo que no está en su lugar, o sea, yo les tengo que dejar muy claro, que creo que es la mayor protección que les puedo dar, es dejarles claro que si alguien cree que hay algo mal en mi familia el problema lo tiene la otra persona, porque ahí les voy a dar la seguridad para defenderse, para sentir que están haciendo bien, para sentir que están seguros de sí mismos, [pero] si estoy diciendo 'mira no digas que papi(s) duermen en el mismo cuarto', porque yo creo que ahí estoy generando el problema para los niños... (...) si había algo de closet que quedaba en mí tengo que eliminarlo por completo... (Octavio, padre en contexto homosexual por acuerdo de coparentalidad).

Como señala Stacey (2006), la paternidad abiertamente gay nunca es accidental. Los hombres que han tenido a sus hijos en el marco de una relación homosexual han debido recorrer un largo camino para alcanzar la paternidad. Este camino les ha significado gran esfuerzo y tomar no pocas decisiones. Ha sido un proceso reflexivo en que probablemente han contado con más tiempo y recursos para plantearse cómo enfrentar su entorno social. Además, estos hombres han conciliado su homosexualidad con la paternidad desde el inicio de esta última. Ellos suelen estar orgullosos de su rol de padres. Como se señaló, Octavio ha optado por ser totalmente abierto respecto a su configuración familiar. De esta forma, él busca proteger a sus hijos y evitar que sean cuestionados. En la siguiente cita Octavio relata cómo les presentó su familia a apoderados de los compañeros de sus hijos 
en una reunión en el jardín. Al explicar su configuración familiar y ser explícito respecto a los vínculos entre sus miembros, Octavio busca anticiparse a los prejuicios y las elucubraciones.

Y aprovechando que estamos todos los padres y estamos todos reunidos, me presento mi nombre es tal, mi esposo, somos los papás de Guillermo y Gabriel junto con Isabella que está ahí, hicimos- trajimos eh el acuerdo para tener hijos, hola Isabella (risas) y eh... corté un poco el hielo, así como de- ya que no fue una infidelidad, si no fue algo como un acuerdo entre los tres, no sé qué, estamos feliz con nuestros hijos bla bla bla, y terminé, esta es mi familia, quería contarles porque... para que nos conocieran, si tienen alguna consulta, bienvenidos, sus hijos ya nos identifican que somos los papás de Guillermo y Gabriel, 'mira llego tu papá, llego tu papi', cuando ellos les digan mis amiguitos tienen dos papás, ustedes sepan de qué están hablando y no digan, 'no, mi amor te equivocaste, no, un papá y una mamá', aquí sí es verdad que tienen dos papás (Octavio, padre en contexto homosexual por acuerdo de coparentalidad).

Una de las principales preocupaciones de los padres es crear entornos seguros para sus hijos. Aquellos que tienen la posibilidad, eligen barrios, establecimientos educacionales, centros de salud, etc, donde piensan que sus configuraciones familiares no serán estigmatizadas. Víctor señala que él ha evitado los ambientes conservadores y se ha preocupado que su hijo esté en un 'entorno amable':

Y por algo yo me he preocupado tanto de que esté en un entorno amable en esta situación que vivimos, no me voy a ir a vivir a los Trapenses [barrio de clase alta y conservador en Santiago], ni voy a ir a meter a mi hijo en un colegio opus dei, tan tonto no soy como para exponerlo a esa situación. Lo que yo estoy haciendo es preparar la mayor cantidad de herramientas posible para que el día de mañana no se sienta afectado por lo mismo en que yo no me siento afectado, ¿cachai? (Víctor, padre en contexto heterosexual).

Los padres están muy conscientes de que uno de los contextos clave donde se desenvolverán sus hijos son las instituciones escolares. Al elegir el colegio al que asistirán los niños se está decidiendo en qué entorno se moverán, quiénes serán sus amigos y a qué tipo de discursos estarán expuestos. Al inicio de este apartado relatamos como Alex debió sacar a su hijo del colegio católico en el que estaba. Por su parte, Octavio sostiene que han buscado un colegio lo más diverso posible para sus hijos, que acoja a niños de distintas nacionalidades y de distintas configuraciones familiares. Señala, "no un colegio que esté orientado a familias tradicionales porque eso va a ser más difícil pa' nosotros" (Octavio, padre en contexto homosexual). Víctor señala que ha hecho todo lo posible para que su hijo crezca en un entorno 'amable'. 
De acuerdo con las experiencias de nuestros participantes, la principal particularidad de la paternidad gay es, precisamente, el tener que diseñar e implementar múltiples estrategias para proteger a sus hijos/as de un entorno hostil. Cuando se le pregunta a Víctor si el ser homosexual ha influido de alguna manera en su paternidad, él responde:

Entonces si tú me dices claro, si esto influye, obvio que sí porque yo he tenido que buscar nuevas respuestas para hacer que el entorno de mi hijo sea un entorno normal, a pesar de que para muchos no lo es. Entonces me ha obligado a buscar colegios específicos para eso, amigos que avalen esta situación, no sé, rodearnos de personas que nos entreguen cariño, porque yo también le estoy mostrando un mundo a mi hijo, y no quiero mostrarle un mundo hostil, entonces sipo ha influido en todo porque es finalmente quién soy yo (Víctor, padre en contexto heterosexual).

Florencio reflexiona sobre cuál es la mejor manera de proteger a su hija. El que el estigma de su hija -el provenir de una familia homoparentalno sea visible hace posible que ‘el secreto' sea un camino viable para protegerla. Florencio afirma que deben protegerla siendo coherente con sus necesidades. Esto implica que los padres deben estar siempre pendientes y alertas para decidir qué estrategias de protección se adaptan mejor a las necesidades actuales de su hija.

Cuando tomamos la decisión de traer a la Sofía a este mundo es la misma decisión que toman todos. Si la Sofía hubiera tenido un ojo por acá abajo, o una pata más corta, si la Sofía... ¿cachai?, se nota, pero a la Sofía no se le nota nada y está en nosotros cómo la vamos a proteger. Si nosotros la vamos a proteger mintiendo, si la vamos a proteger negando, o la vamos a proteger siendo coherentes con las necesidades de ella, y ser coherentes con las necesidades de ella significa que es ella la que va adelante y uno va mirando y va protegiendo (Florencio, padre en contexto heterosexual y homosexual).

El proteger esun proceso, y las estrategias y prácticas de protección que se tomen, de cierre o de apertura, dependerán del contexto e irán cambiando con el tiempo. Pero, lo que es seguro, es que estos padres sienten que deben estar siempre atentos y previendo cómo proteger a sus hijos de la discriminación.

\section{Conclusiones}

Varios autores ponen a las parejas del mismo sexo en la vanguardia de las transformaciones de la intimidad (Giddens, 1992; Beck-Gernsheim, 2002; Weeks et al., 2001). Stacey (2006) afirmaque la paternidad gay transforma la paternidad como la conocemos. Algunos de los elementos que sostienen este argumento son que la paternidad gay: a) es reflexiva (no se da 'naturalmente') y que los hombres homosexuales enfrentan enormes 
obstáculos para alcanzarla; b) no cumple con el paquete ideal de 'matrimonio-trabajo-paternidad', c) enfatiza la paternidad social por sobre la biológica y d) los hombres, no las mujeres, serían los cuidadores primarios de los hijos/as.

Sin embargo, los padres gay, como las madres lesbianas (Herrera, 2009), tienen un discurso más cercano a la asimilación que a la diferenciación. Al igual que en el estudio de Smietana (2013 y 2016) con padres gay que han acudido a la subrogación en España, estos padres están buscando construir familias nucleares, que se asemejen lo más posible a nuestro modelo occidental de familia (Cadoret, 2003; Herrera, 2009). Los padres de este estudio que han tenido hijos en contextos homosexuales están casados (en otros países) o han suscrito el AUC (en Chile) y conviven con sus parejas desde hace muchos años. Es decir, reproducen el modelo de una familia biparental, donde la pareja conyugal es la misma que la pareja parental. Smietana (2016) argumenta que para reparar sus identidades parentales que son vistas como 'anormales'-y lograr la inclusión social, estos padres toman la decisión estratégica de acercarse lo más posible a los guiones normativos de familia (dos adultos en una relación romántica y sexual que conviven con sus hijos/as).

Las experiencias de padres homosexuales no son exclusivas y pueden no estar relacionadas intrínsecamente con su orientación sexual. Los hombres en relaciones heterosexuales con problemas de fertilidad o los padres adoptivos también deben superar importantes obstáculos para tener hijos y también desafían la primacía de los vínculos biológicos (Herrera, 2011 y 2013). Sin duda, que una pareja de hombres sean los cuidadores primarios de un bebé conlleva una desestabilización de los estereotipos de género. Algunos autores plantean que una de las características de las relaciones de pareja homosexuales es que, al no haber diferencia de género, son más igualitarias (Giddens, 1992; Weston, 1991; Weeks et al., 2001; Cadoret, 2003). Por el contrario, Bergman et al. (2010) señalan que no vieron indicios de la 'desgenerización' de la paternidad en su estudio con padres gay. Carrington (1999) sostiene que las parejas homosexuales tienden a invisibilizar la domesticidad para evitar el estigma de la transgresión de las expectativas de género, y que existen otros marcadores de desigualdad (como el estatus y la clase social) que marcan sus relaciones. Para estudiar cómo los hombres gay se reparten las tareas propias de la crianzay evaluar si estas parejas son más democráticas se requiere de una metodología diseñada especialmente con este propósito. Este es un desafío para investigacionesfuturas.

Otro aspecto que es necesario tener en cuenta es la influencia de la clase social y los ingresos económicos en cómo los padres homosexuales experimentan la paternidad. De acuerdo con Stacey (2006) los caminos disponibles para alcanzar la paternidad están directamente relacionados con la disponibilidad de recursos. Criticando la idea de las 'relaciones puras' de Giddens (1992), Jamieson (1999) destaca que existen circunstancias materiales, prácticas y económicas que marcan la forma en que las relaciones 
son construidas y vividas. En este estudio se han visto algunos indicios de cómo los padres con más recursos pueden tener mejores oportunidades para crear un entorno seguro para sus familias, ya que tienen más posibilidades de elegir el barrio, el colegio y los prestadores de salud para sus hijos. Además, los hombres homosexuales con mayor capital social y económico son los que tienen más posibilidades de acceder a la paternidad, lo que nos lleva a pensar cómo se estratifica la reproducción. Este es un aspecto que puede pesar mucho en nuestras sociedades latinoamericanas.

A lo largo de este artículo argumentamos que la paternidad gay no es esencialmente diferente a la paternidad heterosexual y que las experiencias parentales de hombres gay pueden ser similares a las de padres heterosexuales (Bergman et al., 2010; Bos, 2010). Las diferencias estriban en que los padres homosexuales deben a) reinterpretar las ideologías respecto a la familia desafiando estereotipos culturales que asumen que una mujer es necesaria para criar un/a niño/a y b) desarrollar estrategias de protección ya que viven en contextos homofóbicos donde la posibilidad de la discriminación siempre está presente. De esta forma, mostramos cómo un contexto heteronormativo que devalúa a la homosexualidad influye directamente en las experiencias parentales de los hombres gay en Chile.

\section{Agradecimientos}

Agradecemos el apoyo financiero del Fondo Nacional de Desarrollo Científico y Tecnológico de Chile (FONDECYT Regular No 1150554) y el apoyo institucional de la Universidad Diego Portales. También queremos agradecer a los hombres que han confiado en nosotros y tan generosamente han compartido sus experiencias. 


\section{Notas}

${ }^{1}$ Agradecemos el apoyo financiero del Fondo Nacional de Desarrollo Científico y Tecnológico de Chile (FONDECYT Regular $\mathrm{N}^{\circ}$ 1150554) y el apoyo institucional de la Universidad Diego Portales. También queremos agradecer a los hombres que han confiado en nosotros y tan generosamente han compartido sus experiencias.

${ }^{2}$ Entenderemos la homoparentalidad como el ejercicio de la parentalidad por parte de personas homosexuales (Haces, 2006).

${ }^{3}$ Muy posiblemente esta cifra sub-representa a las familias homoparentales. Más información en: http://www.elmercurio.com/blogs/2018/04/15/59509/Heterosexualpor-secretaria.aspx

4 Para más detalles ver: http://www.corteidh.or.cr/cf/Jurisprudencia2/ ficha_tecnica.cfm?nId_Ficha=196\&lang $=e$

${ }^{5}$ Por ejemplo, el derecho de la pareja a adoptar conjuntamente a un niño/a, o la adopción por parte del segundo padre en el caso que sólo uno de ellos sea el padre biológico o legal.

${ }^{6}$ Fuente: https://www.cadem.cl/wp-content/uploads/2017/09/Track-PP190-Septiembre-S1-VF.pdf

${ }^{7}$ Fondecyt Regular $N^{\circ} 1150554$ “Convertirse en padre en Chile hoy: Experiencias masculinas de transición a la paternidad”. Investigadora Responsable: Florencia Herrera.

${ }^{8}$ 1. Socióloga, mujer heterosexual de 44 años, madre (Florencia), 2. Sociólogo, hombre gay sin hijos de 28 años (Yanko), 3 y 4. Sociólogas, mujeres jóvenes heterosexuales sin hijos, en torno a los 27 años (Valentina y Constanza).

${ }^{9}$ No se entrega más información para no comprometer el anonimato de los participantes. 


\section{Bibliografía}

Barrientos, J. E. y Bozon, M. (2014). Discrimination and victimization against gay men and lesbians in Chile: two patterns or just one?. Interdisciplinaria, 31(2), 323-339. doi:10.16888/interd.2014.31.2.8

Barrientos, J. E., Vega, A., Gutierrez, K., Zaffirri, I., yRamirez, P. (2016). Identidad sexual en jóvenes gay del norte de Chile. Sexualidad, Salud y Sociedad (Rio de Janeiro), (23), 118-139. doi: 10.1590/19846487.sess.2016.23.05.a

Beck-Gernsheim, E.(2003) La Reinvención de la Familia. En Busca de Nuevas Formas de Convivencia. Barcelona, España: Paidós - Contextos.

Bergman, K., Rubio, R. J., Green, R.-J., y Padrón, E. (2010). Gay men who become fathers via surrogacy: the transition to parenthood. Journal of GLBT Family Studies, 6(2), 111-141. doi: 10.1080/ 15504281003704942

Berkowitz, D., y Marsiglio, W. (2007). Gay men: negotiating procreative, father, and family identities. Journal of Marriage \& Family, 69(2), 366-381. doi: 10.1111/j.1741-3737.2007.00371.x

Bos, H. H. M. W. (2010). Planned gay father families in kinship arrangements. Australian and New Zealand Journal of Family Therapy, 31(4), 356-371. doi: 10.1375/anft.31.4.356

Bozett, F. W. (1980). Gay fathers: how and why they disclose their homosexuality to their children. Family Relations, 29(2), 173-179. doi: $10.2307 / 584068$

Brown, S., Smalling, S., Groza, V., y Ryan, S. (2009). The experiences of gay men and lesbians in becoming and being adoptive parents. AdoptionQuarterly, 12(3/4), 229-246. doi:10.1080/ 10926750903313294

Cadoret, A. (2003). Padres como los demás: homosexualidad y parentesco. Barcelona, España: Gedisa.

Carrington, C. (1999).No place like home: Relationships and family life among lesbians and gay men.Chicago, IL y London: University of Chicago Press.

CEP (2017). Estudio Nacional de Opinión Pública No 79. Santiago, Chile: Centro de EstudiosPúblicos. 
Deave, T., y Johnson, D. (2008). The transition to parenthood: what does it mean for fathers? Journal of Advanced Nursing, 63(6), 626-633. doi: 10.1111/j.1365-2648.2008.04748.x

Dolan, A., y Coe, C. (2011). Men, masculine identities and childbirth. Sociology of Health \& Illness, 33(7), 1019-1034. https://doi.org/ 10.1111/j.1467-9566.2011.01349.x

Donovan, C. (2000). Who needs a father? Negotiating biological fatherhood in British lesbian families using self-insemination. Sexualities, 3(2), 149-164. doi: 10.1177/136346000003002003

Dunne, G. A. (2000). Opting into motherhood: lesbians blurring the boundaries and transforming the meaning of parenthood and kinship. Gender \& Society, 14(1), 11-35. doi: 10.1177/089124300014001003

Figueroa, V., y Tasker, F. (2014). "I always have the idea of sin in my mind...”: family of origin, religion, and Chilean young gay men. Journal of GLBT Family Studies, 10(3), 269-297. doi:10.1080/ $1550428 X .2013 .834424$

Giddens, A. (1992). The transformation of intimacy. Sexuality, love and eroticism in modern societies. Cambridge, Reino Unido: Polity Press.

Giesler, M. A. (2012). Gay fathers' negotiation of gender role strain: a qualitative inquiry. Fathering: A Journal of Theory, Research, and Practice about Men as Fathers, 10(2), 119-139. doi: 10.3149/ fth.1002.119

Golombok, S., Mellish, L., Jennings, S., Casey, P., Tasker, F., y Lamb, M. E. (2014). Adoptive gay father families: parent-child relationships and children's psychological adjustment. ChildDevelopment, 85(2), 456-468.doi:10.1111/cdev.12155

Haces, M. de los A. (2006). Significado y ejercicio de los roles parentales entre varones homosexuales. La Ventana, 3(23), 127-165.

Hequembourg, A. L., y Farrell, M. P. (1999). Lesbian motherhood: negotiating marginal-mainstream identities. Gender \& Society, 13(4), 540-557. doi: 10.1177/089124399013004007

Herrera, F. (2009). Tradition and transgression: lesbian motherhood in chile. Sexuality Research \& Social Policy, 6(2), 35. doi: 10.1525/ srsp.2009.6.2.35

Herrera, F. (2011). The building of parental bonds: adoption and assisted reproduction in Chile.Revista de cercetaresiinterventie social,32: 25-43. 
Herrera F, Teitelboim B, Russo M, Salas S, ZegersHochschild F (2013) Encuesta de opinión pública sobre reproducción humana y usos de tecnología de reproducción asistida en habitantes de Santiago, Chile. Revista Médica de Chile, 141, 853 - 860.

Herrera, F. (2013). “Men always adopt”: infertility and reproduction from a male perspective. Journal of Family Issues. doi: 10.1177/ $0192513 X 13484278$

Herrera, F., y Pavicevic, Y. (2016). Anticipando la paternidad: “ella es la que está embarazada”. Masculinities and Social Change, 5(2), 107-133. doi:10.17583/MCS.2016.2038

Jamieson, L. (1999)Intimacy transformed? A critical look at the 'pure relationship'.Sociology, 33 (3), 477 - 494.

Laguna, O. E. (2013). Vivir a contracorriente. Arreglos parentales de varones gay en la ciudad de México. Ciudad de México, México: WesthaliaPress

Laguna, O. E. (2016). Arreglos parentales de varones gay en la Ciudad de México: de la paternidad negada a la transformación inadvertida del cuidado. Masculinities and Social Change, 5(2), 182-204. doi: 10.17583/MCS.2016.2033

Lathrop, F. (2017). “Cuidado personal y copaternidad: comentario a la sentencia de la Corte Suprema de Chile de 23 de mayo de 2017 (ROL No 99.861-16)". Revista de derecho (Coquimbo), 24(2), 323-336. https://dx.doi.org/10.4067/S0718-97532017000200323

Lewin, E. (1993). Lesbian mothers: accounts of gender in American culture. Ithaca, NY: Cornell University Press.

Miller, T. (2011). Making sense of fatherhood: gender, caring and work. Cambridge, Reino Unido: Cambridge UniversityPress

Ministerio de Desarrollo Social (2016). Casen 2015: diversidad sexual síntesis de resultados. Recuperado a partir de: http:// observatorio.ministeriodesarrollosocial.gob.cl/casenmultidimensional/casen/docs/CASEN_2015_Resultados _Diversidad_Sexual_18102016.pdf

Murphy, D. A. (2013). The desire for parenthood: gay men choosing to become parents through surrogacy. Journal of Family Issues, 34(8), 1104-1124. doi: 10.1177/0192513X13484272

Norton, W., Hudson, N., y Culley, L. (2013). Gay men seeking surrogacy to achieve parenthood. ReproductiveBiomedicine Online, 27(3), 271279.doi: 10.1016/j.rbmo.2013.03.016 
Olavarría, J. (2001a). Hombres a la deriva?: poder, trabajo y sexo. Santiago, Chile: FLACSO-Chile.

Olavarría, J. (2001b). Y todos querían ser (buenos) padres: varones de Santiago de Chile en conflicto. Santiago, Chile: Flacso-Chile.

Ruiz, J. (2009). Análisis sociológico del discurso: métodos y lógicas. ForumQualitative Social Research, 10(2), Art. 26.doi: 10.17169/fqs10.2.1298

Smietana, M. (2013). Las paternidades y maternidades en las familias de padres gays creadas por gestación subrogada. En J. Bestard, C. López, y D. Marre (Eds.), Procreación, maternidades y crianza en transformación (pp.203-220). Barcelona, España: Bellaterra.

Smietana, M. (2016).Families Like We’d Always Known”? Spanish Gay Fathers' Normalization Narratives in Transnational Surrogacy. En M. Lie, N.Lykke (Eds.), Assisted Reproduction Across Borders Feminist Perspectives on Normalizations, Disruptions and Transmissions. New York, United States: Routledge.

Stacey, J. (2006). Gay parenthood and the decline of paternity as we knew it. Sexualities, 9(1), 27-55. doi: 10.1177/1363460706060687

Taylor, S. J. y Bogdan, R. (1986). Introducción a los métodos cualitativos de investigación. México D.F., México: Paidós.

Valdés, X. (2008). Notas sobre la metamorfosis de la familia en Chile. Recuperado de http://repositorio.cepal.org//handle/11362/6917

Valdés, X. (2009). El lugar que habita el padre en Chile contemporáneo: estudio de las representaciones sobre la paternidad en distintos grupos sociales. El lugar que habita el padre en Chile contemporáneo: Estudio de las representaciones sobre la paternidad en distintos grupos sociales. Polis (Santiago), 8(23), 385-410. Recuperado de https:/ /scielo.conicyt.cl/scielo.php?script=sci_arttext\&pid=S071865682009000200017\&lng=es\&tlng=es .

Weeks, J.,Heaphy, B. y Donovan, C.(2001). Same sex intimacies. Families of choice and other life experiments. London, UK: Routledge.

Weston, K. (1991).Families we choose. Lesbians, gays, kinship. New York, United States: Columbia University Press.

Recibido: 04.05 .18

Aceptado: 31.07 .18 